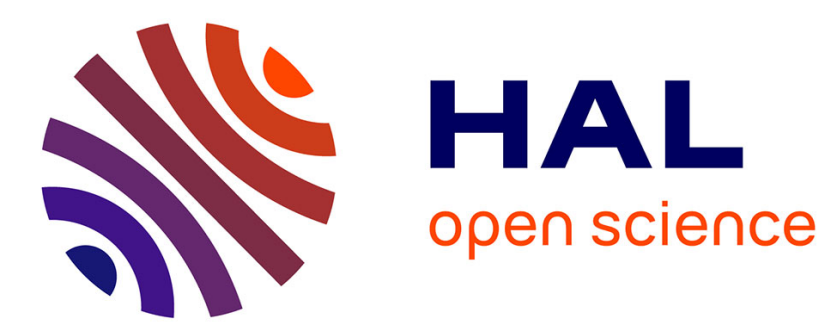

\title{
Répertoire des textes législatifs et réglementaires publiés pendant les mois de novembre 1994 à février 1995
}

- [.]revue Forestière Française, Rédaction

\section{To cite this version:}

- [.]revue Forestière Française, Rédaction. Répertoire des textes législatifs et réglementaires publiés pendant les mois de novembre 1994 à février 1995. 1995, pp.96-97. 10.4267/2042/26631 . hal03535295

\section{HAL Id: hal-03535295 \\ https://hal.science/hal-03535295}

Submitted on 19 Jan 2022

HAL is a multi-disciplinary open access archive for the deposit and dissemination of scientific research documents, whether they are published or not. The documents may come from teaching and research institutions in France or abroad, or from public or private research centers.
L'archive ouverte pluridisciplinaire HAL, est destinée au dépôt et à la diffusion de documents scientifiques de niveau recherche, publiés ou non, émanant des établissements d'enseignement et de recherche français ou étrangers, des laboratoires publics ou privés. 


\section{législation et \\ jurisprudence}

\section{RÉPERTOIRE DES TEXTES LÉGISLATIFS ET RÉGLEMENTAIRES PUBLIÉS PENDANT LES MOIS DE NOVEMBRE 1994 À FÉVRIER 1995}

CODE FORESTIER - CODE RURAL

- Loi

Loi n 95-101 du 2 février 1995 relative au renforcement de la protection de l'environnement.

(J.O. Lois et Décrets, $n^{\circ} 29$ du 3 février 1995, pp. 1840-1856)

Modification du Code rural :

- création du Conseil départemental de l'environnement, du Comité régional de l'environnement :

- plans de préventions des risques naturels prévisibles :

- inventaire départemental du patrimoine naturel ;

- mesures liées à la gestion et la police des espaces naturels :

- gestion des déchets, el des pollutions liées.

Les mesures diverses traitent: du prix de l'eau potable, du transport du gibier, des frais de garde des objets saisis, de l'enfouissement des lignes électriques...

\section{ENVIRONNEMENT}

\section{- Décrets}

Décret $n^{\circ}$ 95-51 du 16 janvier 1995 modifiant le décret $n^{\circ}$ 93-744 du 29 mars 1993 modifié portant création de la commission du développement durable.

(J.O. Lois et Décrets, $n^{\circ} 14$ du 17 janvier 1995, p. 854)

Décret $n^{\circ}$ 95-140 du 6 février 1995 portant publication de la Convention sur la diversité biologique (ensemble deux annexes), adoptée à Rio de Janeiro le 22 mai 1992 et signée par la France le 13 juin 1992.

(J.O. Lois et Décrets, $n^{\circ} 36$ du 11 février 1995, pp. 2312-2320)

Nota : la présente Convention est entrée en vigueur le 29 septembre 1994. 


\section{FFN - REBOISEMENT -}

PLANTS FORESTIERS

\section{- Décret}

Décret $n^{\circ}$ 94-1054 du 1er décembre 1994 relatif à l'attribution d'une prime annuelle destinée à compenser les pertes de revenu découlant du boisement de surfaces agricoles.

(J.O. Lois et Décrets, $n^{\circ} 285$ du 9 décembre 1994, pp. 17468-17470)

\section{- Arrêtés}

Arrêté du 7 octobre 1994 modifiant l'arrêté du 8 juin 1973 relatif aux normes de qualité extérieure des matériels forestiers de reproduction.

(J.O. Lois et Décrets, $n^{\circ} 265$ du 16 novembre 1994, pp. 16234-16235)
Arrêté du 9 janvier 1995 portant modification du règlement relatif au classement et à la qualification des entrepreneurs paysagistes et de reboisement.

(J.O. Lois et Décrets, $n^{\circ} 17$ du 20 janvier 1995 , p. 1069)

\section{FORÊTS DE PROTECTION}

- Décrets

Décrets du 9 décembre 1994 portant classement comme forêt de protection des :

- forêt de Mothern (Bas-Rhin),

- forêt de Sessenheim (Bas-Rhin),

- forêt de Stattmatten (Bas-Rhin),

- forêt de Auenheim (Bas-Rhin).

(J.O. Lois et Décrets, $n^{\circ} 288$ du 12-13 décembre 1994, pp. 17658-17659) 